Revista Brasil. Bot., V.34, n.3, p.247-259, jul.-set. 2011

\title{
Comparação da vegetação arbustivo-arbórea de uma área de cerrado rupestre na Chapada dos Veadeiros, Goiás, e áreas de cerrado sentido restrito do Bioma Cerrado
}

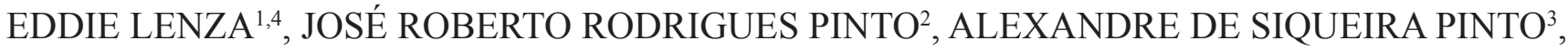 \\ LEANDRO MARACAHIPES $^{1}$ e ELISA PEREIRA BRUZIGUESSI ${ }^{3}$
}

(recebido: 31 de dezembro de 2010; aceito: 01 de abril de 2011)

\begin{abstract}
Comparisons between a savanna on rocky soil tree-shrub community at Chapada dos Veadeiros, Goiás, and cerrado sensu stricto areas of the Cerrado biome). The floristic composition and the structure of a savanna on rocky soil (cerrado rupestre) tree-shrub community, including monocots, in the municipality of Alto Paraíso de Goiás, state of Goiás, were determined. Our objectives were: 1 . To compare floristic and structural aspects between the tree-shrub community studied and 14 other cerrado sensu stricto areas, with and without monocots. 2. To evaluate phytogeography patterns of the 15 compared areas. We sampled 71 species, including five monocots (Velloziaceae $=3$; Arecaceae $=2$ ). Including monocots, the studied community was the most dense $(1,977$ individuals $\left.\mathrm{ha}^{-1}\right)$ and showed the second basal area $\left(11.25 \mathrm{~m}^{2} \mathrm{ha}^{-1}\right)$ among the 15 compared areas. On the other hand, excluding monocots, density and basal area decreased to 892 individuals ha-1 e $7.55 \mathrm{~m}^{2} \mathrm{ha}^{-1}$, respectively. The diversity and equability indices were low $\left(H^{\prime}=2.81 ; J^{\prime}=0.66\right.$, respectively) when monocots were included; however, excluding species of this group, $H^{\prime}$ and $J^{\prime}$ increased to 3.63 and 0.86 , respectively. Increases in richness, density and basal area, with the inclusion of monocots, suggested high importance of Velloziaceae and Arecaceae families in the studied community. The flora was mostly represented by deep-soil cerrado species. Nevertheless, five of the ten highest IV species are considered cerrado rupestre habitat specialists (Vellozia variabilis Mart. ex Schult. f., Wunderlichia cruelsiana Taub., Schwartzia adamantium (Cambess.) Bedell ex Giraldo-Cañas, Hyptis pachyphylla Epling and Vellozia tubiflora (A. Rich.) Kunth). Moreover, the low floristic similarities between the studied community and the others suggest floristic particularity of the Alto Paraíso de Goiás rocky cerrado. The phytogeographical patterns revealed through cluster (UPGMA) and ordination (DCA) analyses indicated the influence of altitude, of geographical closeness between the areas and of their location in relation to the Cerrado neighboring biomes (Amazonian Forest, Atlantic Forest and Caatinga).
\end{abstract}

Key words - conservation, habitat specialist, phytogeography, rocky soils

RESUMO - (Comparação da vegetação arbustivo-arbórea de uma área de cerrado rupestre na Chapada dos Veadeiros, Goiás, e áreas de cerrado sentido restrito do Bioma Cerrado). Foram determinadas a composição florística e a estrutura da vegetação arbustivo-arbórea, incluindo monocotiledôneas, em uma comunidade de cerrado rupestre, no município Alto Paraíso de Goiás, Goiás. Os objetivos desse estudo foram: 1. Comparar os aspectos florísticos e estruturais da área estudada com aqueles de outros 14 estudos com comunidades arbustivo-arbóreas, com e sem a presença de monocotiledôneas, 2. Avaliar os padrões fitogeográficos das 15 áreas comparadas. Foram amostradas 71 espécies, sendo cinco espécies de monocotiledôneas (três Velloziaceae e duas Arecaceae). Considerando as monocotiledôneas, a comunidade inventariada foi a mais densa (1.977 indivíduos ha-1) e apresentou a segunda maior área basal $\left(11,25 \mathrm{~m}^{2} \mathrm{ha}^{-1}\right)$, entre as áreas comparadas. No entanto, sem as monocotiledôneas a densidade e área basal reduziram para 892 indivíduos ha- e $7,55 \mathrm{~m}^{2} \mathrm{ha}^{-1}$, respectivamente. Os índices de diversidade $\left(H^{\prime}=2,81\right)$ e equabilidade $\left(J^{\prime}=0,66\right)$ foram baixos com a presença das monocotiledôneas, mas se elevaram, com a exclusão das espécies desse grupo $\left(H=3,63, J^{\prime}=0,86\right)$. Os aumentos nos valores de riqueza, densidade e área basal, com a inclusão das monocotiledôneas indicaram elevada importância das famílias Velloziaceae e Arecaceae na comunidade de cerrado rupestre estudada. A flora foi representada predominantemente por espécies de cerrado sentido restrito sobre solos profundos. No entanto, cinco das dez espécies com maiores VI são consideradas habitat especialistas de cerrado rupestre (Vellozia variabilis Mart. ex Schult. f., Wunderlichia cruelsiana Taub., Schwartzia adamantium (Cambess.) Bedell ex Giraldo-Cañas, Hyptis pachyphylla Epling e Vellozia tubiflora (A. Rich.) Kunth). Além do mais, foi observada baixa similaridade florística entre a área de estudo e as áreas comparadas, sugerindo particularidade florística do cerrado rupestre de Alto Paraíso de Goiás. Os padrões fitogeográficos, revelados por análises de agrupamento (UPGMA) e ordenação (DCA), indicaram influência da altitude, da proximidade geográfica entre áreas e de suas localizações em relação aos biomas adjacentes ao Cerrado (Floresta Amazônica, Mata Atlântica e Caatinga).

Palavras-chave - afloramentos rochosos, conservação, especialistas de habitat, fitogeografia

1. Universidade do Estado de Mato Grosso, Departamento de Biologia, Programa de Pós-Graduação em Ecologia e Conservação, BR 158, km 148, Caixa Postal 08, 78690-000 Nova Xavantina, MT, Brasil.

2. Universidade de Brasília, Departamento de Engenharia Florestal, Programa de Pós-graduação em Ciências Florestais, Caixa Postal 04357, 70919-970 Brasília, DF, Brasil.
3. Universidade de Brasília, Departamento de Ecologia, Laboratório de Ecologia de Ecossistemas, 70919-900 Brasília, DF, Brasil.

4._Autor para correspondência: eddielenza@yahoo.com.br 


\section{Introdução}

O Cerrado é a savana com maior biodiversidade do mundo (Mittermeier et al. 2005), além de apresentar elevado grau de endemismo da flora e fauna (Mittermeier et al. 2005, Mendonça et al. 2008). Porém, devido principalmente aos desmatamentos para implantação de pastagens e culturas agrícolas, este bioma apresenta apenas 39,5\% de sua área natural preservada (Sano et al. 2010). Segundo Machado et al. (2004), caso não se mude o ritmo de exploração das áreas nativas, até meados deste século a vegetação do Cerrado se restringirá às áreas de Unidades de Conservação, terras indígenas e regiões impróprias à agropecuária.

Entre as diferentes paisagens do Bioma Cerrado, ocorrem os ambientes rupestres que são genericamente chamados de campos rupestres (Eiten 1978), "inselbergs" (Porembski 2007) ou complexos rochosos de altas altitudes (Benites et al. 2007). Dentro deste complexo vegetacional ocorrem fisionomias campestres (campo rupestre), savânicas (cerrado rupestre) e, em menor proporção, formações florestais (Eiten 1978, Oliveira Filho \& Fluminhan Filho 1999, Pinto et al. 2009). O cerrado rupestre ocorre sobre solos rasos, com afloramentos rochosos e geralmente predominam em elevadas altitudes (Eiten 1978, Ribeiro \& Walter 2008), principalmente na Cadeia do Espinhaço (Benites et al. 2007) e na porção norte do Estado de Goiás (Lima 2008).

Apesar da complexidade da paisagem dos ambientes rupestres (Oliveira Filho \& Fluminhan Filho 1999, Lima 2008), do elevado grau de endemismo da flora (Simon \& Proença 2000, Porembski 2007) e da importância estratégica que as áreas de cerrado rupestre representam para a manutenção da biodiversidade do Cerrado (Porembski 2007, Pinto et al. 2009), pouco ainda se sabe sobre a estrutura da vegetação arbustivo-arbórea dos cerrados rupestres do Brasil Central (Oliveira Filho \& Fluminhan Filho 1999, Pinto et al. 2009, Lima et al. 2010). A maioria dos estudos florísticos e fitossociológicos da flora lenhosa do Cerrado foi realizada em áreas com solos profundos e relevo plano a levemente ondulado (Ratter et al. 2003, Fonseca \& Silva Júnior 2004, Felfili et al. 2007a, Mendonça et al. 2008). Assim, pouca ênfase tem sido dada às áreas de campo rupestre e cerrado rupestre, embora representem juntos cerca de $7 \%$ do bioma (Reatto et al. 2008), aproximadamente 6,6\% do Estado de Goiás mais o Distrito Federal e 14\% da área contínua formada pela Área de Proteção do Pouso Alto, incluindo o Parque Nacional da Chapada dos Veadeiros (Lima 2008).

Nesse contexto, foi determinada a composição florística e a estrutura da vegetação arbustivo-arbórea de uma área de cerrado rupestre localizada na região da Chapada dos Veadeiros, Município de Alto Paraíso de Goiás, GO. A partir dessas informações, foram realizadas comparações com estudos já realizados em áreas de cerrado rupestre e de cerrado sentido restrito. Objetivou-se averiguar se áreas de cerrado rupestre apresentam, predominantemente, espécies com ampla distribuição em fisionomias savânicas do bioma Cerrado, bem como menor número de espécies de hábitat restrito (Pinto et al. 2009, Lima et al. 2010), ou hábitat especialistas (sensu Rabinowitz 1981), mas que possuem elevada importância na composição estrutural da comunidade. Foi ainda avaliada a distribuição fitogeográfica da vegetação arbustivo-arbórea em áreas de cerrado rupestre e de cerrado sentido restrito sobre solos profundos, comparando com os padrões descritos na literatura para a vegetação lenhosa das formações savânicas do Bioma Cerrado (Ratter et al. 1996, 2003, Castro \& Martins 1999, Bridgewater et al. 2004) com o intuito de averiguar se esses padrões são mantidos com a inclusão de áreas de cerrado rupestre.

\section{Material e métodos}

Este estudo foi realizado na região da Chapada dos Veadeiros, Município de Alto Paraíso de Goiás, situada na mesorregião norte do Estado de Goiás. O clima da região é do tipo Aw, segundo a classificação de Köppen, com precipitação média anual entre 1.200 e $1.400 \mathrm{~mm}$ e temperatura média anual de $20^{\circ} \mathrm{C}$ (Felfili 2007a, Silva et al. 2008).

Localizada no Domínio de Planaltos em estruturas dobradas, a região da Chapada dos Veadeiros insere-se no Complexo Montanhoso Veadeiros-Araí (Felfili 2007a), onde são encontrados os locais mais altos do Centro-Oeste brasileiro, podendo chegar a mais de $1.600 \mathrm{~m}$ (Ribeiro \& Walter 2008). O relevo varia de plano a fortemente ondulado, onde ocorrem afloramentos rochosos montanhosos e escarpados (Felfili et al. 2007b, c, Lima 2008). Em geral, os solos são rasos, quase sempre pedregosos, representados por Neossolos Litólicos, Cambissolos e Areias Quartzosas associadas aos afloramentos de quartzitos, mas também são encontrados, em pequenas manchas, Latossolos Vermelho-Escuros nos topos aplanados (Felfili 2007a, Haridasan 2007). A vegetação é caracterizada pela ocorrência das diferentes fitofisionomias do bioma Cerrado (sensu Ribeiro \& Walter 2008), sendo o cerrado rupestre e o campo limpo as fitofisionomias mais representativas na região (Munhoz \& Proença 1998, Felfili 2007a).

A comunidade estudada ocorre sobre afloramento rochoso com área aproximada de 20 ha, localizada em propriedade particular, situada adjacente ao Parque Nacional da Chapada dos Veadeiros, posicionada nas coordenadas geográficas $14^{\circ} 09^{\prime} 25,7^{\prime \prime} \mathrm{S}$ e $47^{\circ} 36^{\prime} 25,6^{\prime \prime} \mathrm{W}$ e distante cerca 
de $10 \mathrm{~km}$ da cidade de Alto Paraíso de Goiás, pela rodovia GO 327. Foram demarcadas e georeferenciadas 10 parcelas de $20 \times 50 \mathrm{~m}$, totalizando 1,0 ha de área amostral, conforme recomendado por Felfili et al. (2005). As parcelas foram estabelecidas aleatoriamente nas áreas de afloramentos rochosos, com altitudes que variaram entre 1.180 a $1.210 \mathrm{~m}$ acima do nível do mar e dispostas perpendicularmente a encosta, como sugerido por Oliveira Filho (1994). Foi respeitada a distância mínima de $100 \mathrm{~m}$ entre parcelas para garantir independência das unidades amostrais e melhor representar a possível heterogeneidade e variação florística da comunidade.

O levantamento da vegetação foi realizado no interior das parcelas identificando as espécies e tomando as medidas de altura total e diâmetro do tronco de todos os indivíduos arbustivo-arbóreos vivos (incluindo monocotiledôneas das famílias Velloziaceae e Arecaceae) que apresentaram diâmetro da base igual ou superior a $5 \mathrm{~cm}$, medido a $30 \mathrm{~cm}$ do solo $\left(\mathrm{Db}_{30 \mathrm{~cm}} \geq 5 \mathrm{~cm}\right)$. Para os indivíduos que apresentaram ramificações abaixo de $30 \mathrm{~cm}$ de altura, em relação ao nível do solo, foi calculada a raiz quadrada da soma dos diâmetros das ramificações ao quadrado, ou diâmetro quadrático, conforme adotado por Pinto et al. (2009), pois esse procedimento evita superestimar e subestimar o cômputo dos valores de densidade e área basal da comunidade.

As espécies foram identificadas no campo e nos casos em que isso não foi possível coletou-se material botânico, o qual foi herborizado e identificado através de consultas à literatura específica, a especialistas e ao acervo do Herbário da UnB (UB). O material botânico coletado fértil foi depositado no UB como coleção testemunho. A classificação botânica foi realizada com base no APG (APG III 2009) e os nomes das espécies foram conferidos com a base de dados disponíveis na página eletrônica do Missouri Botany Garden (http://www. mobot.org).

A suficiência amostral, em termos florísticos, foi avaliada por meio da construção de curva de rarefação (Gotelli \& Colwell 2001), com 1.000 aleatorizações, e da comparação entre a riqueza observada e a calculada para a área pelo estimador Jackknife 1 (Magurran 1988), no Programa EstimateS 8.2 (Colwell 2008). A estrutura da vegetação foi descrita com base nos parâmetros fitossociológicos de densidade, frequência, dominância e índice de valor de importância (Müeller-Dombois \& Ellenberg 1974). A diversidade e a equabilidade de espécies foram calculadas através dos índices de diversidade de Shannon-Wiener $\left(H^{\prime}\right)$ e de equabilidade de Pielou $\left(J^{\prime}\right)$, respectivamente (Brower \& Zar 1984). Os parâmetros fitossociológicos e os índices de diversidade e de equabilidade foram calculados no Programa Mata Nativa 2 (Cientec 2006).

As comparações das características florísticas (riqueza, diversidade, equabilidade e similaridade) e estruturais (densidade e área basal) da comunidade estudada e aquelas registradas em áreas de cerrado rupestre e cerrado sentido restrito sobre solos profundos, amostradas no Planalto Central brasileiro, foram realizadas apenas com estudos que adotaram os mesmos métodos, critérios e intensidade de amostragem. Para as comunidades de cerrado sentido restrito sobre solos profundos, sempre que possível, foram selecionados estudos conduzidos em áreas localizadas nas diferentes províncias florísticas do bioma Cerrado (Ratter et al. 1996, 2003, Castro \& Martins 1999, Bridgewater et al. 2004). Para comparar o índice de diversidade registrado na área do presente estudo com o das demais, aplicou-se o teste $t$ de Hutchenson (Zar 1999).

A avaliação fitogeográfica, com base na similaridade florística, entre as áreas de cerrado sentido restrito sobre solos profundos e de cerrado rupestre foi realizada por meio da análise de agrupamento hierárquico, com base na média de grupo (UPGMA) (Sneath \& Sokal 1973), utilizando o programa NTSYS v. 2.1 (Rohlf 2000). O processo de fusão dos grupos se baseou na distância média mínima entre indivíduos e grupos (Kent \& Coker 1992). Esse mesmo conjunto de dados também foi ordenado pelo método de DCA (Análise de correspondência distendida) (Kent \& Coker 1992), através de uma matriz de dados de presença e ausência das espécies em cada uma das 15 áreas, usando o programa Pcord 5 (McCune \& Mefford 2006).

Alguns dos estudos aqui comparados incluíram e outros excluíram da amostragem espécies não lenhosas, como indivíduos das famílias Velloziaceae e Arecaceae. Para permitir comparações padronizadas dos parâmetros comunitários entre as áreas (riqueza, densidade, área basal, $H^{\prime}, J^{\prime}$, UPGMA e DCA), as análises foram realizadas excluindo as espécies dessas duas famílias. No entanto, para aqueles estudos que incluíram espécies não lenhosas, são apresentados os resultados com e sem a presença desse grupo, permitindo assim avaliar os efeitos da exclusão das monocotiledôneas arbustivo-arbóreas sobre os parâmetros florísticos e estruturais das comunidades de cerrado sentido restrito e cerrado rupestre.

\section{Resultados}

Foram amostrados 1.977 indivíduos $\mathrm{ha}^{-1}$, pertencentes a 71 espécies, 49 gêneros e 29 famílias, perfazendo $11,25 \mathrm{~m}^{2} \mathrm{ha}^{-1}$ de área basal total (tabela 1). O índice de diversidade de Shannon-Wiener $\left(H^{\prime}\right)$ foi de 2,81 e o índice de equabilidade de Pielou $(J)$ de 0,66 (tabela 2). Excluindo-se as espécies das famílias Velloziaceae e Arecaceae, os valores de densidade, riqueza e área basal reduzem para 892 indivíduos ha-1, 66 espécies e 7,55 $\mathrm{m}^{2} \mathrm{ha}^{-1}$, respectivamente, enquanto que $H^{\prime}$ ' $J$ ' aumentaram para 3,63 e 0,86 respectivamente (tabelas 1 e 2).

Com base no estimador de riqueza Jackknife 1, o número total esperado para a área foi de 81 espécies. A riqueza registrada contemplou aproximadamente $89 \%$ do número potencial estimado de espécies. Adicionalmente, a curva de acumulação de espécies estabilizou a partir 
Tabela 1. Famílias e espécies arbustivo-arbóreas $\left(\mathrm{Db}_{30 \mathrm{~cm}} \geq 5 \mathrm{~cm}\right)$ registradas no levantamento fitossociológico realizado em um hectare de cerrado rupestre $(10$ parcelas de $20 \times 50 \mathrm{~m})$ no Município de Alto Paraíso de Goiás, GO. (DA = Densidade absoluta; $\mathrm{DR}=$ densidade relativa; $\mathrm{FA}=$ frequência absoluta; $\mathrm{FR}=$ frequência relativa; DoA = dominância absoluta; DoR $=$ dominância relativa). Espécies registradas em menos de 1\% (\#) e em mais de 50\% das áreas (†), compiladas de Ratter et al. (2003); $*$ espécies de habitat especialista.

Table 1. Families and tree-shrub species $\left(\mathrm{Db}_{30 \mathrm{~cm}} \geq 5 \mathrm{~cm}\right)$ sampled in the phytosociological survey in one hectare of cerrado rupestre (10 plots of $20 \times 50 \mathrm{~m}$ ) located in Alto Paraíso de Goiás, state of Goiás. (DA = absolute density; DR = relative density; $\mathrm{FA}=$ absolute frequency; FR = relative frequency; $\mathrm{DoA}=$ absolute dominance; $\mathrm{DoR}=$ relative dominance). Species registered in less than $1 \%(\#)$ and in more than $50 \%$ of the areas $(\dagger)$, compiled by Ratter et al. $2003 ;^{*}=$ habitat specialist species.

\begin{tabular}{|c|c|c|c|c|c|c|c|c|}
\hline ESPÉCIE & FAMÍLIA & DA & $\mathrm{DR}$ & FA & FR & DoA & DoR & VI \\
\hline Vellozia variabilis Mart. ex Schult. f. * & Velloziaceae & 794 & 40,16 & 100 & 3,36 & 2,72 & 24,20 & 67,72 \\
\hline Wunderlichia cruelsiana Taub. \#* & Asteraceae & 62 & 3,14 & 60 & 2,01 & 1,20 & 10,70 & 15,85 \\
\hline $\begin{array}{l}\text { Schwartzia adamantium (Cambess.) Bedell ex } \\
\text { Gir.-Cañas \#* }\end{array}$ & Marcgraviaceae & 35 & 1,77 & 100 & 3,36 & 0,80 & 7,09 & 12,22 \\
\hline Vellozia squamata Jackson & Velloziaceae & 113 & 5,72 & 100 & 3,36 & 0,35 & 3,10 & 12,17 \\
\hline Syagrus flexuosa (Mart.) Becc. & Arecaceae & 101 & 5,11 & 70 & 2,35 & 0,40 & 3,58 & 11,04 \\
\hline $\begin{array}{l}\text { Chamaecrista pachyclada (Harms) H. S. Irwin } \\
\& \text { Barneby }\end{array}$ & Fabaceae & 78 & 3,95 & 60 & 2,01 & 0,39 & 3,49 & 9,45 \\
\hline Hyptis pachyphylla Epling* & Lamiaceae & 72 & 3,64 & 90 & 3,02 & 0,29 & 2,57 & 9,23 \\
\hline Vellozia tubiflora (A. Rich.) Kunth* & Velloziaceae & 63 & 3,19 & 100 & 3,36 & 0,17 & 1,46 & 8,01 \\
\hline Bauhinia pulchella Benth. & Fabaceae & 60 & 3,03 & 60 & 2,01 & 0,28 & 2,53 & 7,58 \\
\hline Ocotea pomaderroides (Meisn.) Mez \# & Lauraceae & 19 & 0,96 & 80 & 2,68 & 0,33 & 2,96 & 6,61 \\
\hline Callisthene mollissima Warm. & Vochysiaceae & 29 & 1,47 & 20 & 0,67 & 0,48 & 4,29 & 6,43 \\
\hline $\begin{array}{l}\text { Schefflera macrocarpa (Cham. \& Schltdl.) } \\
\text { Frodin }\end{array}$ & Araliaceae & 42 & 2,12 & 70 & 2,35 & 0,21 & 1,83 & 6,31 \\
\hline Macairea radula (Bonpl.) DC. & Melastomataceae & 33 & 1,67 & 80 & 2,68 & 0,15 & 1,35 & 5,70 \\
\hline Vochysia thyrsoidea Pohl & Vochysiaceae & 29 & 1,47 & 60 & 2,01 & 0,24 & 2,16 & 5,64 \\
\hline Myrcia sp. & Myrtaceae & 30 & 1,52 & 80 & 2,68 & 0,12 & 1,09 & 5,29 \\
\hline Mimosa manidea Barneby \# & Fabaceae & 26 & 1,32 & 90 & 3,02 & 0,08 & 0,74 & 5,07 \\
\hline Copaifera oblongifolia Mart. \# & Fabaceae & 10 & 0,51 & 50 & 1,68 & 0,30 & 2,64 & 4,82 \\
\hline Erythroxylum suberosum A. St.-Hil. $\dagger$ & Erythroxylaceae & 22 & 1,11 & 80 & 2,68 & 0,07 & 0,61 & 4,41 \\
\hline Byrsonima pachyphylla A. Juss. $\uparrow$ & Malpighiaceae & 26 & 1,32 & 70 & 2,35 & 0,07 & 0,62 & 4,29 \\
\hline Palicourea rigida Kunth & Rubiaceae & 26 & 1,32 & 60 & 2,01 & 0,08 & 0,69 & 4,02 \\
\hline Aspidosperma multiflorum A. DC. & Apocynaceae & 17 & 0,86 & 30 & 1,01 & 0,23 & 2,06 & 3,93 \\
\hline Tachigali vulgaris L. G. Silva \& H. C. Lima & Fabaceae & 12 & 0,61 & 50 & 1,68 & 0,15 & 1,32 & 3,60 \\
\hline Vochysia elliptica Mart. & Vochysiaceae & 14 & 0,71 & 70 & 2,35 & 0,05 & 0,44 & 3,50 \\
\hline Qualea parviflora Mart. $\dagger$ & Vochysiaceae & 7 & 0,35 & 50 & 1,68 & 0,16 & 1,40 & 3,43 \\
\hline Byrsonima coccolobifolia Kunth $\dagger$ & Malpighiaceae & 15 & 0,76 & 50 & 1,68 & 0,09 & 0,76 & 3,20 \\
\hline Eremanthus glomerulatus Less. & Asteraceae & 12 & 0,61 & 60 & 2,01 & 0,03 & 0,29 & 2,91 \\
\hline Myrcia sellowiana O. Berg & Myrtaceae & 8 & 0,40 & 40 & 1,34 & 0,11 & 1,01 & 2,75 \\
\hline Byrsonima intermedia A. Juss. & Malpighiaceae & 13 & 0,66 & 40 & 1,34 & 0,08 & 0,74 & 2,74 \\
\hline Ilex congesta $\mathrm{H} . \mathrm{W} . \mathrm{Li}$ & Aquifoliaceae & 7 & 0,35 & 40 & 1,34 & 0,11 & 0,93 & 2,63 \\
\hline Myrsine guianensis (Aubl.) Kuntze & Myrsinaceae & 8 & 0,40 & 40 & 1,34 & 0,08 & 0,70 & 2,45 \\
\hline Wunderlichia mirabilis Riedel ex Baker \#* & Asteraceae & 10 & 0,51 & 40 & 1,34 & 0,07 & 0,62 & 2,47 \\
\hline Hancornia speciosa Gomes $\dagger$ & Apocynaceae & 7 & 0,35 & 50 & 1,68 & 0,04 & 0,37 & 2,40 \\
\hline $\begin{array}{l}\text { Chamaecrista orbiculata (Benth.) H. S. Irwin } \\
\text { \& Barneby }\end{array}$ & Fabaceae & 21 & 1,06 & 20 & 0,67 & 0,07 & 0,62 & 2,36 \\
\hline Kielmeyera lathrophyton Saddi & Clusiaceae & 6 & 0,30 & 50 & 1,68 & 0,05 & 0,40 & 2,38 \\
\hline Simarouba versicolor A. St.-Hil. & Simaroubaceae & 6 & 0,30 & 40 & 1,34 & 0,08 & 0,71 & 2,35 \\
\hline Styrax ferrugineus Nees \& Mart. & Styracacaeae & 7 & 0,35 & 50 & 1,68 & 0,04 & 0,31 & 2,34 \\
\hline Agarista chapadensis (Kin.-Gouv.) Judd & Ericaceae & 5 & 0,25 & 30 & 1,01 & 0,11 & 1,02 & 2,28 \\
\hline Syagrus comosa (Mart.) Mart. & Arecaceae & 14 & 0,71 & 30 & 1,01 & 0,06 & 0,57 & 2,29 \\
\hline
\end{tabular}


continuação

\begin{tabular}{|c|c|c|c|c|c|c|c|c|}
\hline ESPÉCIE & FAMÍLIA & DA & $\mathrm{DR}$ & FA & FR & DoA & DoR & VI \\
\hline Ouratea glaucescens Engl. & Ochnaceae & 5 & 0,25 & 50 & 1,68 & 0,03 & 0,28 & 2,21 \\
\hline Humiria balsamifera Aubl. & Humiriaceae & 2 & 0,10 & 20 & 0,67 & 0,16 & 1,40 & 2,17 \\
\hline Mimosa claussenii Benth. & Fabaceae & 9 & 0,46 & 40 & 1,34 & 0,02 & 0,20 & 2,00 \\
\hline Neea theifera Oerst. & Nyctaginaceae & 6 & 0,30 & 40 & 1,34 & 0,04 & 0,34 & 1,98 \\
\hline Vochysia gardneri Warm. & Vochysiaceae & 6 & 0,30 & 40 & 1,34 & 0,03 & 0,28 & 1,93 \\
\hline Emmotum nitens (Benth.) Miers & Icacinaceae & 3 & 0,15 & 20 & 0,67 & 0,12 & 1,02 & 1,85 \\
\hline $\begin{array}{l}\text { Couepia grandiflora (Mart. \& Zucc.) Benth. ex } \\
\text { Hook. f. }\end{array}$ & Chrysobalanaceae & 5 & 0,25 & 40 & 1,34 & 0,02 & 0,21 & 1,80 \\
\hline Myrcia canescens $\mathrm{O}$. Berg & Myrtaceae & 9 & 0,46 & 30 & 1,01 & 0,04 & 0,31 & 1,77 \\
\hline Eugenia punicifolia (Kunth) DC. & Myrtaceae & 7 & 0,35 & 30 & 1,01 & 0,03 & 0,24 & 1,60 \\
\hline Connarus suberosus Planch. & Connaraceae & 7 & 0,35 & 30 & 1,01 & 0,02 & 0,17 & 1,53 \\
\hline Erythroxylum sp. & Erythroxylaceae & 3 & 0,15 & 20 & 0,67 & 0,08 & 0,67 & 1,49 \\
\hline Erythroxylum tortuosum Mart. & Erythroxylaceae & 5 & 0,25 & 30 & 1,01 & 0,02 & 0,18 & 1,44 \\
\hline Miconia ferruginata DC. & Melastomataceae & 5 & 0,25 & 30 & 1,01 & 0,02 & 0,16 & 1,42 \\
\hline Heteropterys byrsonimifolia A. Juss. & Malpighiaceae & 4 & 0,20 & 30 & 1,01 & 0,02 & 0,17 & 1,38 \\
\hline Plenckia populnea Reissek & Celastraceae & 5 & 0,25 & 20 & 0,67 & 0,04 & 0,37 & 1,29 \\
\hline Eremanthus goyazensis (Gardner) Sch. Bip. & Asteraceae & 4 & 0,20 & 20 & 0,67 & 0,02 & 0,17 & 1,04 \\
\hline Ferdinandusa elliptica (Pohl) Pohl & Rubiaceae & 6 & 0,30 & 10 & 0,34 & 0,05 & 0,42 & 1,06 \\
\hline Miconia albicans (Sw.) Steud. & Melastomataceae & 3 & 0,15 & 20 & 0,67 & 0,01 & 0,07 & 0,89 \\
\hline Myrcia rostrata DC. & Myrtaceae & 2 & 0,10 & 20 & 0,67 & 0,01 & 0,12 & 0,89 \\
\hline Ouratea hexasperma (A. St.-Hil.) Baill. $\dagger$ & Ochnace & 2 & 0,10 & 20 & 0,67 & 0,01 & 0,12 & 0,89 \\
\hline Miconia irwinii Wurdack \# & Melastomataceae & 2 & 0,10 & 20 & 0,66 & 0,01 & 0,10 & 0,86 \\
\hline Kielmeyera coriacea Mart. \& Zucc. $\dagger$ & Clusiaceae & 2 & 0,10 & 20 & 0,67 & 0,01 & 0,08 & 0,85 \\
\hline Mimosa ulei Taub. & abac & 2 & & 20 & 0,67 & 0,01 & 0 , & 0,83 \\
\hline ii Triana & 1 & 3 & & 10 & 0 , & 0 & 0 , & 0,67 \\
\hline carnosa Cambess. & Per & 2 & & 10 & & 0 , & 0 , & 0,61 \\
\hline Tetrapterys microphylla Nied. & Malpighiaceae & 1 & & 10 & 0,34 & 0,02 & 0,18 & 0,57 \\
\hline Andira vermifuga Mart. ex Benth. & Fabaceae & 2 & 0,1 & 10 & 0,34 & 0,01 & 0,06 & 0,49 \\
\hline Psidium myrsinoides $\mathrm{O}$. Berg & Myrtaceae & 1 & 0,05 & 10 & 0,34 & 0,01 & 0,10 & 0,48 \\
\hline Blepharocalyx salicifolius (Kunth) O. Berg & Myrtaceae & 1 & 0,05 & 10 & 0,34 & 0,01 & 0,06 & 0,45 \\
\hline Cybianthus gardneri (A. DC.) G. Agostini & Myrsinaceae & 1 & 0,05 & 10 & 0,34 & 0,01 & 0,06 & 0,44 \\
\hline Aniba heringeri Vattimo & Lauraceae & 1 & 0,05 & 10 & 0,34 & 0,01 & 0,05 & 0,44 \\
\hline Banisteriopsis latifolia (A. Juss.) B. Gates & Malpighiaceae & 1 & 0,05 & 10 & 0,34 & 0,01 & 0,03 & 0,41 \\
\hline Miconia rubiginosa (Bonpl.) DC. & Melastomataceae & 1 & 0,05 & 10 & 0,34 & 0,01 & 0,03 & 0,41 \\
\hline Total & & 1.977 & 100 & 2.980 & 100 & 11,25 & 100 & 300 \\
\hline
\end{tabular}

da sexta parcela (figura 1), na qual já haviam sido registradas 65 espécies (90,2\% do total amostrado). Assim, podemos assumir que a suficiência amostral, em termos florísticos, avaliada pela curva de rarefação e pela estimativa da riqueza potencial da área, sugere que a amostragem adotada foi representativa da área de cerrado rupestre estudada.

As dez espécies mais abundantes foram Vellozia variabilis, Vellozia squamata, Syagrus flexuosa, Chamaecrista pachyclada, Hyptis pachyphylla, Vellozia tubiflora, Wunderlichia cruelsiana, Bauhinia pulchella, Schefflera macrocarpa e Schwartzia adamantium (tabela 1). Estas espécies (13,9\% do total) representam $71,8 \%$ dos indivíduos amostrados, com destaque para elevadas abundâncias de Vellozia variabilis (794 indivíduos ha-1), Vellozia squamata (113) e Syagrus flexuosa (101). Por outro lado, foram amostradas seis espécies consideradas localmente raras, ou seja, que apresentaram um indivíduo por hectare, sendo elas Tetrapterys microphylla, Psidium myrsinoides, Cybianthus gardneri, Miconia rubiginosa, Banisteriopsis latifolia e Aniba heringeri, que juntas correspondem a $8,3 \%$ da riqueza e $0,3 \%$ da densidade registrada na área (tabela 1 ).

Em termos estruturais, novamente merece destaque Vellozia variabilis, cujo valor de importância (VI) representou $22,6 \%$ do VI total da comunidade, devido principalmente a sua elevada densidade $(40,14 \%$ da densidade total) (tabela 1). As espécies com segundo e 
Tabela 2. Parâmetros florísticos e estruturais de estudos fitossociológicos, utilizando método de parcelas (1 hectare), com espécies arbustivo-arbóreas $\left(\mathrm{Db}_{30 \mathrm{~cm}} \geq 5 \mathrm{~cm}\right)$ em áreas de cerrado rupestre e de cerrado sentido restrito sobre solos profundos, em ordem decrescente de altitude. $(\dagger=$ Bridgewater et al. $2004-$ Províncias: $\mathrm{NE}=$ Nordeste, $\mathrm{CO}=$ Centro Oeste, $\mathrm{CSE}=\mathrm{Central}$ e Sudeste; * = apenas indivíduos vivos; $\mathrm{S}=$ número de espécies; $\mathrm{AB}=$ área basal; $H^{\prime}$ = índice de diversidade de Shannon-Wiener e $J^{\prime}=$ índice equabilidade de Pielou. $I S=$ índice de similaridade de Sørensen com a área do presente estudo; $t=$ teste $\mathrm{t}$ de Hutcheson para comparação dos $I S$ e --- = Sem informação).

Table 2. Floristic and structure parameters of phytosociological studies, using plots establishment method (1 hectare), with tree-shrub species $\left(\mathrm{Db}_{30 \mathrm{~cm}} \geq \mathrm{cm}\right)$ in cerrado rupestre and deep-soil cerrado sensu stricto areas, in altitude descending order. $(\dagger=$ Bridgewater et al. 2004 - Provinces: $\mathrm{NE}=$ Northeast, $\mathrm{CO}=$ Midwest, $\mathrm{CSE}=$ Central e Southeast; $*$ = only a live individuals; $\mathrm{S}=$ number of species; $\mathrm{AB}=$ basal area; $H^{\prime}=$ Shannon-Wiener diversity index e $J^{\prime}=$ Pielou equability index. $I S=$ Sørensen similarity index with the present area; $t=$ Hutcheson's t-test for the $I S$ comparison and --- = No information).

\begin{tabular}{|c|c|c|c|c|c|c|c|c|c|}
\hline \multirow[t]{2}{*}{ Localização } & $\begin{array}{l}\text { Altitude } \\
\text { (m) }\end{array}$ & $\begin{array}{l}\text { Província } \\
\text { florística } \dagger\end{array}$ & $\mathrm{S}$ & $\begin{array}{l}\text { Densidade } \\
\text { Ind. ha }{ }^{-1 *}\end{array}$ & $\begin{array}{c}\mathrm{AB} \\
\left(\mathrm{m}^{2} \mathrm{ha}^{-1}\right)^{*}\end{array}$ & $H^{\prime}$ & $J$ & $I S$ & $T$ \\
\hline & \multicolumn{9}{|c|}{ Cerrado rupestre } \\
\hline $\begin{array}{l}\text { Pirenópolis-GO (Três } \\
\text { Picos) })^{\mathrm{IX}}\end{array}$ & 1.341 & CSE & 56 & 461 & 3,48 & 3,33 & 0,82 & 0,31 & $\mathrm{t}_{(2)}=5,12 ; P<0,05$ \\
\hline Pirenópolis-GO (Portal) ${ }^{\mathrm{X}}$ & 1.310 & CSE & 65 & 972 & 10,02 & 3,65 & 0,87 & 0,35 & $\mathrm{t}_{(2)}=0,46 ; P>0,05$ \\
\hline Cocalzinho-GO ${ }^{\mathrm{I}}$ & 1.200 & CSE & $\begin{array}{c}64 \\
(65)\end{array}$ & $\begin{array}{c}673 \\
(674)\end{array}$ & $\begin{array}{c}5,65 \\
(5,70)\end{array}$ & $\begin{array}{c}3,45 \\
(3,45)\end{array}$ & $\begin{array}{c}0,83 \\
(0,83)\end{array}$ & 0,38 & $\mathrm{t}_{(2)}=3,41 ; P<0,05$ \\
\hline Alto Paraíso-GO ${ }^{\mathrm{XIV}}$ & 1.186 & $\mathrm{CO}$ & $\begin{array}{c}66 \\
(71)\end{array}$ & $\begin{array}{c}892 \\
(1.977)\end{array}$ & $\begin{array}{c}7,55 \\
(11,25)\end{array}$ & $\begin{array}{l}3,63 \\
(2,81)\end{array}$ & $\begin{array}{c}0,86 \\
(0,66)\end{array}$ & $\begin{array}{l}--- \\
---\end{array}$ & -- \\
\hline Brasília-DF ${ }^{I I}$ & 1.050 & CSE & 51 & 607 & 3,59 & 3,09 & --- & 0,37 & $\mathrm{t}_{(2)}=9,35 ; P<0,05$ \\
\hline Mossâmedes-GOVII & 783 & $\mathrm{CO}$ & 54 & 1.137 & 6,92 & 3,13 & 0,79 & 0,27 & $\mathrm{t}_{(2)}=10,63 ; P<0,05$ \\
\hline \multirow[t]{2}{*}{ Caldas Novas-GO } & 686 & CSE & $\begin{array}{c}65 \\
(66)\end{array}$ & $\begin{array}{l}1.355 \\
(1.357)\end{array}$ & $\begin{array}{c}12,37 \\
(12,39)\end{array}$ & $\begin{array}{c}3,33 \\
(3,33)\end{array}$ & $\begin{array}{c}0,80 \\
(0,79)\end{array}$ & $\begin{array}{c}0,30 \\
---\end{array}$ & $\mathrm{t}_{(2)}=7,04 ; P<0,05$ \\
\hline & \multicolumn{9}{|c|}{ Cerrado sentido restrito sobre solos profundos } \\
\hline Brasília-DFVI & 1.100 & CSE & $\begin{array}{c}54 \\
(58)\end{array}$ & $\begin{array}{c}1.042 \\
(1.132)\end{array}$ & $\begin{array}{l}--- \\
---\end{array}$ & $\begin{array}{l}--- \\
---\end{array}$ & $\begin{array}{l}-- \\
---\end{array}$ & --- & 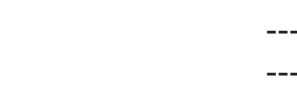 \\
\hline Brasília-DF (interflúvio) $^{\mathrm{IV}}$ & 1.056 & CSE & 53 & 1.174 & 8,18 & 3,16 & --- & 0,34 & $\mathrm{t}_{(2)}=9,85 ; P<0,05$ \\
\hline 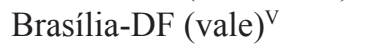 & 1.056 & CSE & 50 & 935 & 6,53 & 3,40 & --- & 0,34 & $\mathrm{t}_{(2)}=5,36 ; P<0,05$ \\
\hline Brasília-DF ${ }^{I I I}$ & 1.000 a 1.050 & CSE & 54 & 818 & 8,97 & 3,41 & --- & 0,29 & $\mathrm{t}_{(2)}=4,73 ; P<0,05$ \\
\hline Paraopeba-MG ${ }^{\mathrm{XIII}}$ & 734 a 750 & CSE & $\begin{array}{c}72 \\
(73)\end{array}$ & $\begin{array}{c}1.810 \\
(1.813)\end{array}$ & $\begin{array}{c}16,38 \\
(16,42)\end{array}$ & $\begin{array}{c}3,59 \\
(3,57)\end{array}$ & $\begin{array}{c}0,84 \\
(0,83)\end{array}$ & $\begin{array}{c}0,30 \\
---\end{array}$ & $\mathrm{t}_{(2)}=1,00 ; P>0,05$ \\
\hline Água Boa-MT & 450 a 500 & $\mathrm{CO}$ & 73 & 925 & 7,10 & 3,69 & 0,84 & 0,17 & $\mathrm{t}_{(2)}=1,23 ; P>0,05$ \\
\hline Canarana-MT ${ }^{\mathrm{XI}}$ & 375 a 400 & $\mathrm{CO}$ & 88 & 1.250 & 9,36 & 3,78 & 0,84 & 0,24 & $\mathrm{t}_{(2)}=3.24 ; P<0,05$ \\
\hline Carolina-MA ${ }^{\mathrm{XV}}$ & 150 & $\mathrm{NE}$ & 53 & 533 & 6,73 & 3,04 & 0,77 & 0,18 & $\mathrm{t}_{(2)}=9,33 ; P<0,05$ \\
\hline
\end{tabular}

I = Pinto et al. (2009), II = Amaral et al. (2006), III = Assunção \& Felfili (2004), IV = Fonseca \& Silva Júnior (2004) (interflúvio), V= Fonseca \& Silva Júnior (2004) (vale), VI = Walter \& Guarino (2006), VII = Miranda et al. (2007), VIII = Lima et al. (2010), IX = Moura et al. (2007) (três picos), X= Moura (2006) (portal), XI = Nogueira et al. (2001), XII = Felfili et al. (2002), XIII = Balduino et al. (2005), XIV = Presente estudo e XV = Medeiros et al. (2008). Os estudos I, VI, VIII, XIII e XIV, amostraram espécies das famílias Velloziaceae e Arecaceae, mas para permitir comparações entre esses estudos e os demais, são apresentados os resultados com (entre parênteses) e sem as espécies dessas duas famílias

I = Pinto et al. (2009), II = Amaral et al. (2006), III = Assunção \& Felfili (2004), IV = Fonseca \& Silva Júnior (2004) (interfluve), V= Fonseca \& Silva Júnior (2004) (valley), VI = Walter \& Guarino (2006), VII = Miranda et al. (2007), VIII = Lima et al. (2010), IX = Moura et al. (2007) (três picos), X= Moura (2006) (portal), XI = Nogueira et al. (2001), XII = Felfili et al. (2002), XIII = Balduino et al. (2005), XIV = Present study and XV = Medeiros et al. (2008). Studies I, VI, VIII, XIII e XIV sampled Velloziaceae and Arecaceae species, but in order to performed comparisons between these studies and another ones, we present results with (parenthesis) and without species these two families.

terceiro maiores VI foram, respectivamente, Wunderlichia cruelsiana (5,27\% do VI total) e Schwartzia adamantium (4,06\%), ocuparam posição de destaque na estrutura da comunidade em função dos elevados valores de área basal individual (1,2 $\mathrm{m}^{2} \mathrm{ha}^{-1}$ e $0,8 \mathrm{~m}^{2} \mathrm{ha}^{-1}$, respectivamente). As outras sete espécies mais importantes em ordem decrescente de VI foram Vellozia squamata, Syagrus flexuosa, Chamaecrista pachyclada, Hyptis pachyphylla, Vellozia tubiflora, Bauhinia pulchella e Callisthene mollissima. Juntas essas dez espécies contribuíram com $53,2 \%$ e $61,7 \%$ dos valores totais de VI e área basal, respectivamente (tabela 1 ). 


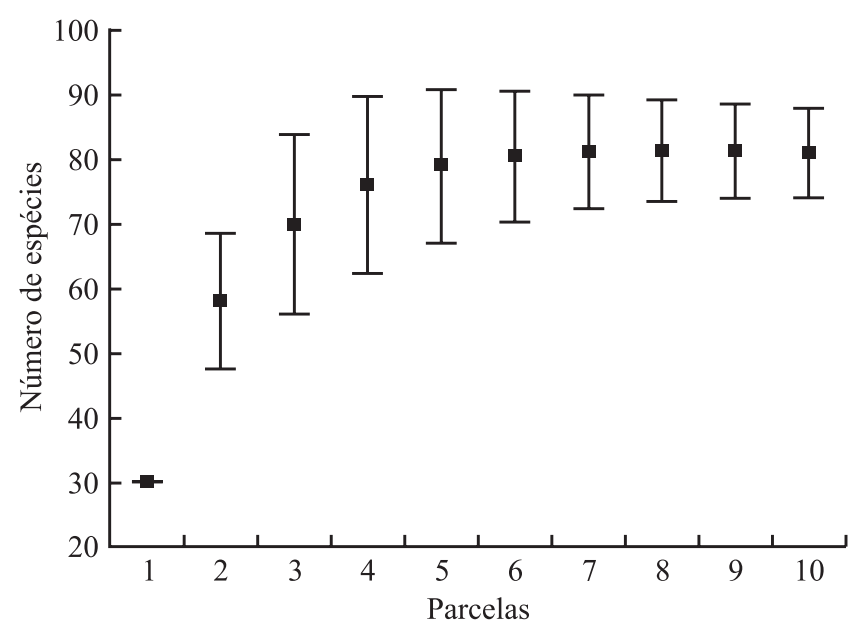

Figura 1. Curva de rarefação (Jackknife 1) para as espécies arbustivo-arbóreas $\left(\mathrm{Db}_{30 \mathrm{~cm}} \geq 5 \mathrm{~cm}\right)$, registradas em 10 parcelas de $20 \times 50 \mathrm{~m}$, amostradas em uma área de cerrado rupestre no Município de Alto Paraíso de Goiás, GO.

Figure 1. Rarefaction curve (Jackknife 1) of the treeshrub species $\left(\mathrm{Db}_{30 \mathrm{~cm}} \geq 5 \mathrm{~cm}\right)$ registered within 10 plots of $20 \times 50 \mathrm{~m}$ sampled in a cerrado rupestre area located in Alto Paraíso de Goiás, GO.

A mediana do diâmetro da comunidade foi de $6,37 \mathrm{~cm}$ e os maiores valores foram registrados para Humiria balsamifera $(44,0 \mathrm{~cm})$ e Callisthene molissima $(39,0 \mathrm{~cm})$. A comunidade estudada apresentou ainda pequeno porte, em termos de altura, com baixos valores médios (1,84 $\mathrm{m} \pm 1,24 \mathrm{~m} \mathrm{DP})$ e medianos $(1,60 \mathrm{~m})$. As maiores alturas foram para Vochysia elliptica $(7,7 \mathrm{~m}) \mathrm{e}$ Sclerolobium paniculatum (7,3 m), que compõem, assim, o extrato superior da vegetação.

A partir da análise de agrupamento por UPGMA, tomando como nível de corte a similaridade $\geq 0,30$, conforme sugerido Gauch (1982), foi possível identificar três grupos formados por duas ou mais áreas e a separação de três outras áreas isoladas. O primeiro grupo foi composto por oito sítios de cerrado rupestre e de cerrado sentido restrito sobre solos profundos do Planalto Central em altitudes entre $700 \mathrm{~m}$ a $1.200 \mathrm{~m}$. O segundo foi formado por dois sítios de cerrado rupestre em elevadas altitudes acima de $1.300 \mathrm{~m}$. O terceiro grupo composto por dois sítios de cerrado sentido restrito sobre solo profundo em baixas altitudes no estado de Mato Grosso (entre 400 e $500 \mathrm{~m}$ ). As demais áreas foram representadas por sítios isolados de cerrado sentido restrito sobre solos profundos, localizados em áreas periféricas do bioma Cerrado (Paraopeba-MG e Carolina-MA), além da área de cerrado rupestre do presente estudo (figura 2).

Esses padrões foram parcialmente confirmados na análise de ordenação - DCA (figura 3), na qual o

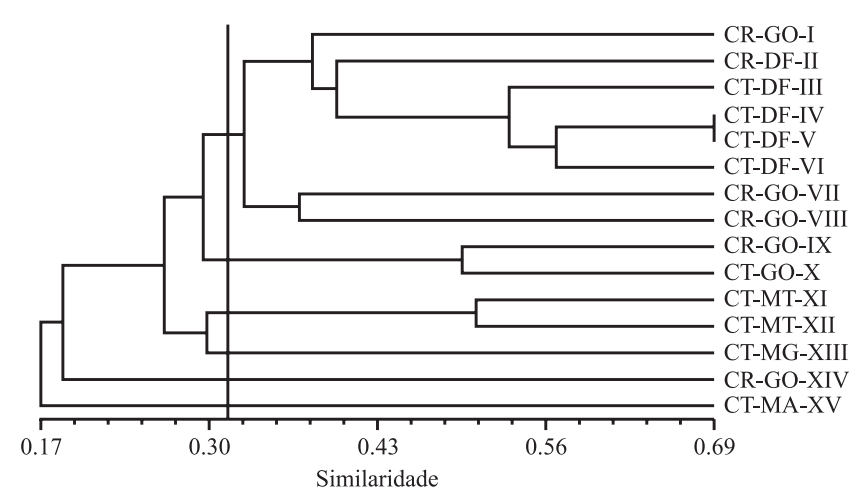

Figura 2. Dendrograma de similaridade florística para as espécies arbustivo-arbóreas $\left(\mathrm{Db}_{30 \mathrm{~cm}} \geq 5 \mathrm{~cm}\right)$, obtido pelo método de ligação UPGMA entre áreas de cerrado rupestre e cerrado sentido restrito sobre solos profundos. $(\mathrm{CT}=$ cerrado típico, $\mathrm{CR}=$ cerrado rupestre, $\mathrm{GO}=$ Goiás, $\mathrm{DF}=$ Distrito Federal, MT = Mato Grosso, MA = Maranhão e MG = Minas Gerais). Ver referência das áreas na tabela 2.

Figure 2. Dendrogram of floristic similarity for the tree-shrub species $\left(\mathrm{Db}_{30 \mathrm{~cm}} \geq 5 \mathrm{~cm}\right)$, obtained by the UPGMA linkage method between cerrado rupestre and deep-soil cerrado sensu stricto areas. $(\mathrm{CT}=$ typical cerrado (cerrado sensu stricto), $\mathrm{CR}=$ cerrado rupestre, $\mathrm{GO}=$ state of Goiás, $\mathrm{DF}=$ Federal District, $\mathrm{MT}=$ state of Mato Grosso, MA = state of Maranhão e MG = state of Minas Gerais). Check Table 2 for the areas' references.

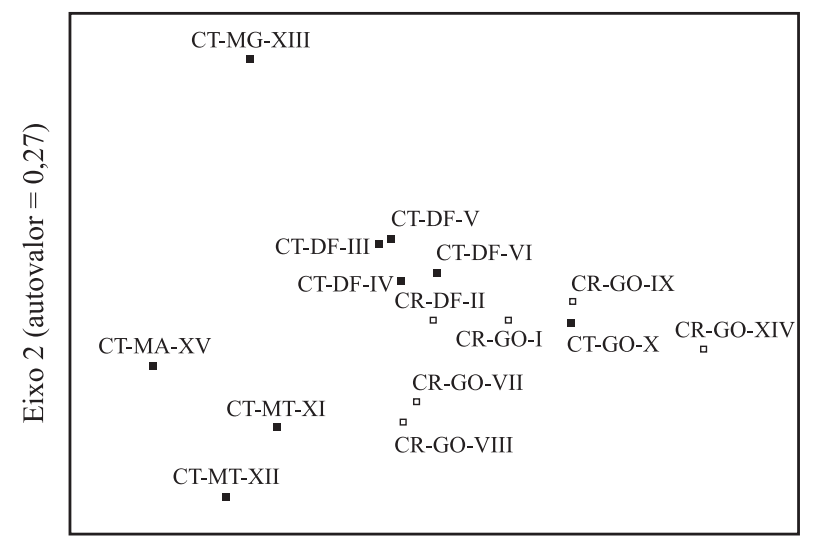

Eixo 1 (autovalor $=0,48)$

Figura 3. Ordenação pelo método DCA, com base na vegetação arbustivo-arbóreas $\left(\mathrm{Db}_{30 \mathrm{~cm}} \geq 5 \mathrm{~cm}\right)$ amostradas em áreas de cerrado rupestre e cerrado sentido restrito sobre solos profundos. (CT = cerrado típico ( $(\square), \mathrm{CR}=$ cerrado rupestre ( $\square$ ), $\mathrm{GO}=$ Goiás, $\mathrm{DF}=$ Distrito Federal, $\mathrm{MT}=$ Mato Grosso, $\mathrm{MA}=$ Maranhão e $\mathrm{MG}=$ Minas Gerais). Ver referência das áreas na tabela 2 .

Figure 3. Ordination by DCA method, based on the tree-shrub community $\left(\mathrm{Db}_{30 \mathrm{~cm}} \geq 5 \mathrm{~cm}\right)$ sampled in cerrado rupestre and deep-soil cerrado sensu stricto areas. (CT $=$ typical cerrado (घ) (cerrado sensu stricto), $\mathrm{CR}=$ cerrado rupestre ( $\square$ ), $\mathrm{GO}=$ state of Goiás, $\mathrm{DF}=$ Federal District, $\mathrm{MT}=$ state of Mato Grosso, MA = state of Maranhão e MG = state of Minas Gerais). Check Table 2 for the areas' references. 
primeiro eixo separou: 1. Áreas de cerrado rupestre e cerrado sentido restrito sobre solos profundos do Planalto Central, sítios I a VIII (Goiás e Distrito Federal), posicionadas na parte central do diagrama; 2 . Áreas de cerrado rupestre em Goiás acima de $1.300 \mathrm{~m}$ de altitude, sítios IX e X; 3. Áreas de cerrado sentido restrito sobre solos profundos localizadas no Estado de Mato Grosso (sítios XI e XII), posicionadas no quadrante inferior esquerdo do diagrama; e duas áreas isoladas, o sítio XV, cerrado sentido restrito em solo profundo no Maranhão, e o sítio XIV, cerrado rupestre do presente estudo. O segundo eixo separou o sítio XIII, amostrado em Paraopeba, $\mathrm{MG}$, em área de cerrado sentido restrito sobre solo profundo, posicionando-o no quadrante superior esquerdo do diagrama, como uma das áreas de menor similaridade florística com as demais, semelhante ao observado na análise de classificação.

A divergência florística, revelada pela UPGMA e DCA entre o cerrado rupestre de Alto Paraíso de Goiás e as demais áreas comparadas, foi também evidenciada pela baixa similaridade florística, cujos índices de Sørensen foram sempre inferiores a 0,4 , independente do tipo de substrato (tabela 2).

\section{Discussão}

A riqueza da flora arbustivo-arbórea registrada no presente estudo (71 espécies com monocotiledôneas e 66 espécies sem monocotiledôneas) foi a maior entre as áreas de cerrado rupestre comparadas e semelhante àquela registrada em áreas de cerrado sentido restrito sobre solos profundos com elevada riqueza florística, amostradas no Brasil Central (tabela 2). Compilações de dados em áreas de cerrado sentido restrito, feitas por Fonseca \& Silva Júnior (2004) e por Felfili et al. (2004, 2007a) para o Planalto Central brasileiro, também evidenciaram tendência da vegetação savânica da região da Chapada dos Veadeiros apresentar elevada riqueza arbustivo-arbórea. Estudo desenvolvido por Prevedello \& Carvalho (2006) com modelagem computacional com dados de campo e conhecida como "Método Pan Geográfico" também apontam a Chapada dos Veadeiros como uma das 11 regiões mais importantes para a conservação da riqueza e biodiversidade da flora do bioma Cerrado.

A Chapada dos Veadeiros é ainda considerada um dos centros de endemismos de espécies vegetais (Simon \& Proença 2000). Essas informações são corroboradas pelas análises de classificação e ordenação aqui realizadas e pelo estudo de Felfili et al. $(2004,2007$ c) que indicaram elevada dissimilaridade florística entre os cerrados da
Chapada dos Veadeiros e outras áreas do Planalto Central brasileiro. A Chapada dos Veadeiros está entre as regiões com mais elevadas altitudes do bioma Cerrado (Felfili et al. 2007a, Ribeiro \& Walter 2008), além de apresentar extensas áreas de formações savânicas sobre relevo acidentado e solos rochosos (Silva et al. 2006, Felfili et al. 2007c, Lima 2008). Segundo Simon \& Proença (2000) essas características abióticas podem explicar a peculiaridade florística e o elevado endemismo em espécies do gênero Mimosa na região.

Apesar da elevada riqueza florística, os índices de diversidade de Shannon-Wiener $\left(H^{\prime}=2,81\right)$ e de equabilidade de Pielou $\left(J^{\prime}=0,66\right)$, quando se considera as monocotiledôneas, são os mais baixos já encontrados em relação às áreas de cerrado rupestre comparadas (tabela 2). Esse fato se deve a elevada abundância de Vellozia variabilis, Vellozia squamata, Syagrus flexuosa e Vellozia tubiflora, uma vez que estes índices, de acordo com Magurran (1988), são baseados na abundância relativa das espécies e reduzem quando há domínio numérico de uma ou poucas espécies na comunidade. No entanto, quando as monocotiledôneas foram excluídas das análises, houve reduções de $7 \%$ na riqueza de espécies e os índices de $H^{\prime}$ e $J$ ' assumiram valores elevados (3,63 e 0,86 , respectivamente) e configuraram entre os mais altos entre todas as áreas comparadas (tabela 2).

Desse modo, as elevadas densidades e a importância estrutural de monocotiledôneas no cerrado rupestre de Alto Paraíso de Goiás, também registradas por Walter \& Guarino (2006) em cerrado típico do Distrito Federal, chamam a atenção para a necessidade de estudos florísticos e fitossociólogicos em fitofisionomias savânicas do bioma Cerrado, incluírem espécies das famílias Velloziaceae e Arecaceae. Muitas vezes essas famílias são ignoradas no processo de amostragem, uma vez que dos 15 estudos aqui comparados apenas cinco incluíram as monocotiledôneas nos levantamentos da vegetação.

Das 38 espécies lenhosas consideradas por Ratter et al. (2003) como de ampla distribuição no Cerrado, ou seja, aquelas registradas em mais de $50 \%$ das 376 áreas de cerrado sentido restrito compiladas pelos autores, apenas sete delas foram registradas no cerrado rupestre estudado $(9,7 \%$ do total de espécies amostradas no presente estudo): Byrsonima pachyphylla, Erythroxylum suberosum, Qualea parviflora, Byrsonima coccolobifolia, Hancornia speciosa, Ouratea hexasperma e Kielmeyera coriacea. Por outro lado, também sete espécies - Wunderlichia cruelsiana, Schwartzia adamantium, Ocotea pomaderroides, Mimosa manidea, Copaifera oblongifolia, Wunderlichia mirabilis e Miconia irwinii 
- inventariadas neste estudo, foram registradas em até três das 376 áreas avaliadas $(<1 \%)$ por Ratter et al. (2003), sendo aqui consideradas raras no bioma Cerrado e conferindo certa peculiaridade florística ao cerrado rupestre da Chapada dos Veadeiros.

Essa peculiaridade é confirmada pela baixa similaridade florística registrada entre a área do presente estudo e as demais áreas comparadas, mesmo com a exclusão das monocotiledôneas (índice de similaridade de Sørensen sempre inferior a 0,4). Apesar de geralmente baixos, os valores mais elevados de similaridade florística, foram sempre registrados com áreas de cerrado sentido restrito sobre solos profundos e cerrado rupestre em elevadas altitudes do Planalto Central brasileiro (acima de $1.000 \mathrm{~m}$ ) e pertencentes à Província Florística Central e Sudeste (CSE - sensu Bridgetwater et al. 2004) (tabela 2), sugerindo maior semelhança florística entre as formações savânicas de elevadas altitudes do Brasil Central. Assim, os padrões fitogeográficos evidenciados por outros autores (Ratter et al. 1996, 2003, Castro \& Martins 1999, Felfili et al. 2007b), para áreas de cerrados sobre solos profundos, foram mantidos mesmo após a inclusão de áreas de cerrado rupestre.

Algumas espécies aqui amostradas são citadas na literatura como habitat especialistas (sensu Rabinowitz 1981), ou seja, de distribuição restrita a ambientes rupestres como: Wunderlichia cruelsiana, Schwartzia adamantium, Wunderlichia mirabilis e Hyptis pachyphylla (Munhoz \& Proença 1998, Ratter et al. 2000, Mendonça et al. 2008, Ribeiro \& Walter 2008), Vellozia variabilis (Silva et al. 2001) e Vellozia tubiflora (Munhoz \& Proença 1998). Wanderley (1989) afirmou ainda que $W$. cruelsiana é restrita apenas à região da Chapada dos Veadeiros. Todas estas espécies, com exceção de $W$. mirabilis, estão entre as dez de maior VI na comunidade e, portanto, configuram-se como importantes na determinação da estrutura da comunidade estudada (tabela 1). Destaca-se ainda que Schwartzia adamantium e Wunderlichia mirabilis apresentaram elevados valores de área basal e de altura, sendo assim determinantes também na estrutura horizontal e vertical da comunidade.

Considerando ainda que as dez espécies mais importantes na estrutura da comunidade estudada representam mais da metade do VI total (tabela 1), nota-se que o cerrado rupestre amostrado na Chapada dos Veadeiros difere marcadamente dos demais cerrados rupestres já estudados no Brasil Central. Apenas Schwartzia adamantium foi citada entre as dez com maior VI no estudo de Pinto et al. (2009) e somente Wunderlichia cruelsiana foi inventariada no estudo de
Amaral et al. (2006), com apenas dois indivíduos e baixo valor de VI. O cerrado rupestre inventariado em Caldas Novas-GO (Lima et al. 2010) foi aquele que apresentou maior semelhança em relação às espécies com maior importância estrutural, pois Wunderlichia cruelsiana e Schwartzia adamantium também destacaram em Valores de Importância (VI) naquele estudo, apesar da similaridade florística entre as duas áreas ter sido baixa $(\mathrm{IS}=0,30)$.

A inclusão das espécies de monocotiledôneas nas análises também causou grandes mudanças na densidade e área basal registradas no cerrado rupestre de Alto Paraíso de Goiás. Dessa forma, considerando as monocotiledôneas, os valores de densidade (1.977 indivíduos ha-1) e área basal $\left(11,25 \mathrm{~m}^{2} \mathrm{ha}^{-1}\right)$ do presente estudo estão entre os maiores já registradas para fitofisionomias de cerrado rupestre e cerrado sentido restrito sobre solos profundos (tabela 2). Por outro lado, quando as espécies de monocotiledôneas são excluídas, a densidade (892 indivíduos ha-1) e área basal $\left(7,55 \mathrm{~m}^{2} \mathrm{ha}^{-1}\right)$ em Alto Paraíso de Goiás estão entre os menores valores registrados para áreas de cerrado típico e rupestre. Assim, a comunidade estudada apresentou estrutura horizontal pouco comum se comparada com outras áreas de cerrado rupestre e de cerrado sentido restrito, particularmente em função da elevada abundância das espécies de monocotiledôneas, como Vellozia variabilis $(n=794$ indivíduos), V. squamata ( $n=113)$, V.tubiflora $(n=63)$ e Syagrus flexuosa $(n=101)$. Essas características florísticas e estruturais garantem o desenvolvimento de uma vegetação muito peculiar e chamam novamente a atenção para a necessidade de se incluir espécies de monocotiledôneas em futuros estudos estruturais da vegetação arbustivo-arbórea.

Os baixos valores medianos de diâmetro $(6,37 \mathrm{~cm})$ bem como as alturas médias e mediana, inferiores a 2 metros, registradas no presente estudo indicam que a estrutura vertical do cerrado rupestre estudado é predominantemente subarbustiva e arbustiva, semelhante ao descrito por Ribeiro \& Walter (2008) em que áreas de cerrado rupestre, em geral, possuem em média 2 a $4 \mathrm{~m}$ de altura. Segundo Pinto et al. (2009), a vegetação arbustivo-arbórea do cerrado rupestre apresenta estrutura da comunidade semelhante às áreas de cerrado ralo do bioma (sensu Ribeiro \& Walter 2008). No entanto, estudos fitossociológicos conduzidos em cerrados rupestres do Brasil Central registraram alturas medianas mais elevadas ((3,18 m em Moura et al. (2010), 2,70 m em Pinto et al. 2009)), sugerindo ampla variação na estrutura vertical dos cerrados rupestres, que podem estar associadas a fatores locais, ainda não investigados. 
Os resultados encontrados no presente estudo são, em partes, corroborados pelos achados de Pinto et al. (2009) e Lima et al. (2010), de que a vegetação arbustivoarbórea em áreas de cerrado rupestre do Planalto Central brasileiro é composta predominantemente por espécies típicas e de ampla distribuição nas formações savânicas sobre solos profundos e com poucas espécies de habitat especialistas, mas com elevada importância na estrutura da comunidade. Dessa forma, há, de fato, seleção de algumas espécies arbustivo-arbóreas mais adaptadas a ambientes rupestres, mas com flora típica de formações savânicas sobre solos mais profundos e cuja distribuição geográfica não é homogênea, provavelmente em função das diferentes altitudes e da influência florística de biomas adjacente, como discutido a seguir.

As análises fitogeográficas conjuntas das áreas de cerrado rupestre e cerrado sentido restrito sobre solos profundos indicaram, por um lado, que áreas em altitudes elevadas e médias do Brasil Central apresentaram maior semelhança florística, concordando com as afirmações de diferentes autores de que a altitude exerce forte influência sobre a flora do Cerrado (Castro \& Martins 1999, Ratter et al. 1996, 2003, Bridgewater et al. 2004). Por outro lado, a proximidade geográfica do bioma Floresta Amazônica (áreas XI e XII, no Estado do Mato Grosso); Mata Atlântica (área XII, em Minas Gerais); e Caatinga (área XV, no Maranhão) coincidiu com a formação de três grupos, sugerindo a influência florística de biomas adjacentes sobre a flora lenhosa do cerrado sentido restrito, como sugerido por Méio et al. (2003) para áreas de transição com os biomas Mata Atlântica e Floresta Amazônica e por Castro \& Martins (1999) em áreas de transição com a Caatinga.

No entanto, os resultados aqui encontrados não evidenciam, inequivocamente, o padrão latitudinal proposto por Castro \& Martins (1999), provavelmente porque a influência latitudinal predita pelos autores é mascarada pela influência florística dos três biomas adjacentes ao Cerrado. Finalmente, não houve agrupamento claro entre áreas pertencentes às mesmas províncias florísticas propostas por Bridgewater et al. 2004. Em resumo, as análises fitogeográficas sugerem forte influência da altitude, da proximidade geográfica entre áreas, bem como da posição geográfica da área em relação aos biomas adjacentes ao Cerrado. Sugerimos a condução de novos estudos, com metodologia padronizada, em áreas de cerrado rupestre e suas inclusões em novas análises fitogeográficas para confirmar os resultados aqui encontrados.

Diferentes estudos têm citado a região da Chapada dos Veadeiros como área prioritária para a conservação da flora e fauna do bioma Cerrado (Felfili et al. 2004, Prevedello \& Carvalho 2006, Mendonça et al. 2007, Felfili et al. 2007b). A Chapada dos Veadeiros é a região com maior representatividade de cerrados rupestres do Estado de Goiás (Lima 2008), além de apresentar alta riqueza florística (presente estudo, Felfili et al. 2007a, Mendonça et al. 2007), particularidade florística (presente estudo, Ratter et al. 1996, Munhoz \& Proença 1998) e elevada heterogeneidade geomorfológica e edáfica (Haridasan 2007, Lima 2008). Segundo Felfili (2007b), a única Unidade de Conservação na região é insuficiente para manutenção da elevada riqueza e heterogeneidade florística. Sugerimos, portanto, que novas Unidades de Conservação sejam criadas na mesorregião da Chapada dos Veadeiros, preservando assim o mosaico vegetacional dessa região com importante e peculiar patrimônio florístico e genético do Bioma Cerrado.

Agradecimentos - À Prof ${ }^{\mathfrak{a}}$ Carolyn Proença, Prof ${ }^{a}$ Lúcia Helena Soares Silva (UnB - Botânica), Prof. Manoel Cláudio da Silva Júnior (UnB - Engenharia Florestal) e ao Dr. Benedito Alísio da Silva Pereira (IBGE) pela ajuda na identificação botânica. Ao Igor A. A. Oliveira e Gabriel Damasco do Valle pela ajuda nos trabalhos de campo. Ao Sr. Narciso por disponibilizar sua propriedade para realização deste estudo. Ao $\mathrm{CNPq} / \mathrm{UnB}$ pela concessão da bolsa de Iniciação Científica à Elisa Pereira Bruziguessi. À Fundação Grupo Boticário de Proteção à Natureza pelo financiamento da pesquisa.

\section{Referências bibliográficas}

AMARAL, A.G., PEREIRA, F.F.O. \& MUNHOZ, C.B.R. 2006. Fitossociologia de uma área de cerrado rupestre da Fazenda Sucupira, Brasília, DF. Cerne 12:350-359.

APG III. 2009. An update of the Angiosperm Phylogeny Group classification for the orders and families of flowering plants: APG III. Botanical Journal of the Linnean Society 161:105-121.

ASSUNÇÃO, S.L. \& FELFILI, J.M. 2004. Fitossociologia de um fragmento de cerrado sensu stricto na APA do Paranoá, DF, Brasil. Acta Botanica Brasilica 18:903-909.

BALDUINO, A.P.C., SOUZA, A.L., MEIRA-NETO, J.A.A., SILVA, A.F. \& SILVA JÚNIOR, M.C. 2005. Fitossociologia e análise comparativa da composição florística do cerrado da flora de Paraopeba-MG. Revista Árvore 29:25-34.

BENITES, V.M., SCHAEFER, C.E.G.R., SIMAS, F.N.B. \& SANTOS, H.G. 2007. Soils associated with rock outcrops in the Brazilian mountain ranges Mantiqueira and Espinhaço. Revista Brasileira de Botânica 30: 569-577. 
BRIDGEWATER, S., RATTER, J.A. \& RIBEIRO, J.F. 2004. Biogeographic patterns, $\beta$ diversity and dominance in the cerrado biome of Brazil. Biodiversity and Conservation 13:2295-2318.

BROWER, J.E. \& ZAR, J.H. 1984. Field and laboratory methods for general ecology. WM.C. Brown, Dubuque.

CASTRO, A.A.J.F. \& MARTINS, F.R. 1999. Cerrados do Brasil e do Nordeste: caracterização, área de ocupação e considerações sobre a sua fitodiversidade. Pesquisa em Foco 7:147-178.

CIENTEC - Consultoria e Desenvolvimento de Sistemas. 2006. Mata Nativa 2. Manual do usuário. Viçosa.

COLWELL, R.K. 2008. EstimateS: Statistical estimation of species richness and shared species from samples. Version 8.0. http://www.purl.oclc.org/estimates (acesso em 15/11/2008).

EITEN, G. 1978. Delimitation of the cerrado concept. Vegetatio 36:169-178.

FELFILI, J.M. 2007a. A Chapada dos Veadeiros. In Biogeografia do bioma Cerrado: vegetação e solos da Chapada dos Veadeiros (J.M. Felfili, A.V. Rezende, M.C. Silva Júnior, orgs.). Editora Universidade de Brasília/Finatec, Brasília, p.15-23.

FELFILI, J.M. 2007b. Recomendações de manejo. In Biogeografia do bioma Cerrado: vegetação e solos da Chapada dos Veadeiros (J.M. Felfili, A.V. Rezende, M.C. Silva Júnior, orgs.). Editora Universidade de Brasília/Finatec, Brasília, p.239-242.

FELFILI, J.M., NOGUEIRA, P.E., SILVA JÚNIOR, M.C., MARIMON, B.S. \& DELITTI, W.B.C. 2002. Composição florística e fitossociológica do cerrado sentido restrito no município de Água Boa-MT. Acta Botanica Brasilica 16:103-112.

FELFILI, J.M., SILVA JÚNIOR, M.C., SEVILHA, A.C., FAGG, C.W. WALTER, B.M.T., NOGUEIRA, P.E \& REZENDE, A.V. 2004. Diversity, floristic and structural patterns of cerrado vegetation in Central Brazil. Plant Ecology 175:37-46.

FELFILI, J.M., CARVALHO, F.A. \& HAIDAR, R.F. 2005. Manual para o monitoramento de parcelas permanentes nos biomas Cerrado e Pantanal. Universidade de Brasília, Departamento de Engenharia Florestal, Brasília.

FELFILI, J.M., REZENDE, A.V., SILVA JÚNIOR, M.C., NOGUEIRA, P.E., WALTER, B.M.T., ENCINAS, J.I. \& SILVA, M.A. 2007a. Fitossociologia da vegetação arbórea. In Biogeografia do bioma Cerrado: vegetação e solos da Chapada dos Veadeiros (J.M. Felfili, A.V. Rezende, M.C. Silva Júnior, orgs.). Editora Universidade de Brasília/Finatec, Brasília, p.45-96.

FELFILI, J.M., SILVA JÚNIOR, M.C., WALTER, B.M.T., REZENDE, A.V., NOGUEIRA, P.E. \& FELFILI, M.C. 2007b. Comparação dentro e entre sistemas de terra na Chapada dos Veadeiros. In Biogeografia do bioma Cerrado: vegetação e solos da Chapada dos Veadeiros (J.M. Felfili, A.V. Rezende, M.C. Silva Júnior, orgs.). Editora Universidade de Brasília/Finatec, Brasília, p.97-110.
FELFILI, J.M., SILVA JÚNIOR, M.C., REZENDE, A.V., NOGUEIRA, P.E. \& FELFILI M.C. 2007c. Comparação entre unidades fisiográficas: Chapada Pratinha e Chapada dos Veadeiros. In Biogeografia do bioma Cerrado: vegetação e solos da Chapada dos Veadeiros (J.M. Felfili, A.V. Rezende, M.C. Silva Júnior, orgs.). Editora Universidade de Brasília/Finatec, Brasília, p.111-117.

FONSECA, M.S. \& SILVA JÚNIOR, M.C. 2004. Fitossociologia e similaridade florística entre trechos de Cerrado sentido restrito em interflúvio e em vale no Jardim Botânico de Brasília, DF. Acta Botanica Brasilica 18:19-29.

GAUCH, H.G. 1982. Multivariate analysis in community ecology. Cambridge University Press, Cambridge.

GOTELLI, N.J. \& COLWELL, R.K. 2001. Quantifying biodiversity: procedures and pitfalls in the measurement and comparison of species richness. Ecology Letters 4:379-391.

HARIDASAN, M. 2007. Solos. In Biogeografia do bioma Cerrado: vegetação e solos da Chapada dos Veadeiros (J.M. Felfili, A.V. Rezende, M.C. Silva Júnior, orgs.). Editora Universidade de Brasília/Finatec, Brasília, p.25-43.

KENT, M. \& COKER, P. 1992. Vegetation description and analysis; a practical approach. Belhaven Press, London.

LIMA, C.P. 2008. O cerrado rupestre no estado de Goiás com base em imagens Landsat ETM+. Dissertação de mestrado, Universidade de Brasília, Brasília.

LIMA, T.A., PINTO, J.R.R., LENZA, E. \& PINTO, A.S. 2010. Florística e estrutura da vegetação arbustivoarbórea em uma área de cerrado rupestre no Parque Estadual da Serra de Caldas Novas, Goiás. Biota Neotropica 10:1-8.

MACHADO, R.B., RAMOS NETO, M.B., PEREIRA, P.G.P., CALDAS, E., GONÇALVES, D.A., SANTOS, N.S., TABOR, K. \& STEININGER, M. 2004. Estimativas de perda da área do Cerrado brasileiro. Relatório técnico não publicado. Conservação Internacional, Brasília.

MAGURRAN, A.E. 1988. Ecological diversity and its measurement. Croom Helm., London.

MCCUNE, B. \& MEFFORD, M.J. 2006. PC-ORD. Multivariate analysis of ecological data, version 5.15. MjM Software, Gleneden Beach.

MEDEIROS, M.B., WALTER, B.M. \& SILVA, G.P. 2008. Fitossociologia do cerrado stricto sensu no município de Carolina, MA, Brasil. Cerne 14: 285-294.

MÉIO, B.B., FREITAS, C.V., JATOBÁ, L., SILVA, M.E.F., RIBEIRO, J.F. \& HENRIQUES, R.P.B. 2003. Influência da flora das florestas Amazônica e Atlântica na vegetação do cerrado sensu stricto. Revista Brasileira de Botânica 26:437-444. 
MENDONÇA, R.C., FILGUEIRAS, T.S. \& FAGG, C.W. 2007. Análise florística da Chapada dos Veadeiros. In Biogeografia do bioma Cerrado: vegetação e solos da Chapada dos Veadeiros (J.M. Felfili, A.V. Rezende \& M.C. Silva Júnior, eds.). Editora Universidade de Brasília/Finatec, Brasília, p.119-237.

MENDONÇA, R.C., FELFILI, J.M., WALTER, B.M.T., SILVAJÚNIOR, M.C., REZENDE, A.V., FILGUEIRAS, T.S., NOGUEIRA, P.E. \& FAGG, C.W. 2008. Flora vascular do cerrado: Chechlist com 12.356 espécies. In Cerrado: ecologia e flora (S.M. Sano, S.P. Almeida \& J.F. Ribeiro, eds.). Embrapa-CPAC, Planaltina, p.417-1279.

MIRANDA, S.C., SILVA JÚNIOR, M.C. \& SALLES, L.A. 2007. A comunidade lenhosa de cerrado rupestre na Serra Dourada, Goiás. Heringeriana 1:43-53.

MITTERMEIER, R.A., ROBLES, P., HOFFMANN, M., PILGRIM, J., BROOKS, T., MITTERMEIER, C.G., LAMOREUX, J. \& FONSECA, G.B. 2005. Hotspots revisited: earth's biologically richest and most endangered ecoregions. Conservation International, Mexico City.

MOBOT - Missouri Botanical Garden. W3 Tropicos 2010. Disponível em http://www.mobot.org/ (acesso em 20/07/2010).

MOURA, I.O. 2006. Fitossociologia de cerrado sensu stricto em afloramentos rochosos no Parque Estadual dos Pireneus, Pirenópolis, Goiás. Dissertação de mestrado, Universidade Federal de Goiás, Goiânia.

MOURA, I.O., KLEIN, V.L.G., FELFILI, J.M. \& FERREIRA, H.D. 2007. Fitossociologia da comunidade lenhosa de uma área de cerrado rupestre no Parque Estadual dos Pirineus, Pirenópolis, Goiás. Revista de Biologia Neotropical 4:83-100.

MOURA, I.O., KLEIN, V.L.G., FELFILI, M.J. \& FERREIRA, H.D. 2010. Diversidade e estrutura comunitária de cerrado sensu stricto em afloramentos rochosos no Parque Estadual dos Pireneus, Goiás. Revista Brasileira de Botânica 33:455-467.

MÜELLER-DOMBOIS, D. \& ELLENBERG, H. 1974. Aims and methods of vegetation ecology. Wiley and Sons, New York.

MUNHOZ, C.B.R. \& PROENÇA, C.E.B. 1998. Composição florística do Município de Alto Paraíso de Goiás na Chapada dos Veadeiros. Boletim do Herbário Ezechias Paulo Heringer 3:102-105.

NOGUEIRA, P.E., FELFILI, J.M. \& SILVA JÚNIOR, M.C. 2001. Composição florística e fitossociologia do cerrado sentido restrito no município de CanaranaMT. Boletim do Herbário Ezechias Paulo Heringer 8:28-43.

OLIVEIRA FILHO, A.T. 1994. Estudos ecológicos da vegetação com subsídios para programas de revegetação com espécies nativas: uma proposta metodológica. Cerne 1:64-72.
OLIVEIRA FILHO, A.T. \& FLUMINHAN FILHO, M. 1999. Ecologia da vegetação do Parque Florestal Quedas do Rio Bonito. Cerne 5:51-64.

PINTO, J.R.R., LENZA, E. \& PINTO, A.S. 2009. Composição florística e estrutura da vegetação arbustivo-arbórea em um Cerrado Rupestre, Cocalzinho de Goiás, Goiás. Revista Brasileira de Botânica 32:23-32.

POREMBSKI, S. 2007. Tropical inselbergs: habitat types, adaptive strategies and diversity patterns. Revista Brasileira de Botânica 30:579-586.

PREVEDELLO, J.A. \& CARVALHO, C.J.B. 2006. Conservação do Cerrado brasileiro: o método panbiogeográfico como ferramenta para a seleção de áreas prioritárias. Natureza e Conservação 4:39-57.

RABINOWITZ, D. 1981. Seven forms of rarity. In The biological aspects of rare plant conservation (H. Synge, ed.). John Wiley, Chichester, p.205-217.

RATTER, J.A., BRIDGEWATER, S., ATKINSON, R. \& RIBEIRO, J.F. 1996. Analysis of the floristic composition of the Brazilian cerrado vegetation II: comparison of the woody vegetation of 98 areas. Edinburgh Journal of Botany 53:153-180.

RATTER, J.A., BRIDGEWATER, S., RIBEIRO, J.F., DIAS, T.A.B. \& SILVA, M.R. 2000. Estudo preliminar da distribuição das espécies lenhosas da fitofisionomia cerrado sentido restrito nos estados compreendidos pelo bioma cerrado. Boletim do Herbário Ezechias Paulo Heringer 5:5-43.

RATTER, J.A., BRIDGEWATER, S. \& RIBEIRO, J.F. 2003. Analysis of the floristic composition of the Brazilian cerrado vegetation III: comparison of the woody vegetation of 376 areas. Edinburgh Journal of Botany 60:57-109.

REATTO, A., CORREIA, J.R., SPERA, S.T. \& MARTINS, E.S. 2008. Solos do bioma Cerrado: aspectos pedológicos. In Cerrado: ecologia e flora (S.M. Sano, S.P. Almeida \& J.F. Ribeiro, eds.). Embrapa-CPAC, Planaltina, p.107-150.

RIBEIRO, J.F. \& WALTER, B.M.T. 2008. Fitofisionomias do bioma Cerrado. In Cerrado: ecologia e flora (S.M. Sano, S.P. Almeida \& J.F. Ribeiro, eds.). Embrapa-CPAC, Planaltina, p.151-212.

ROHLF, F.J. 2000. NTSYS-pc: numerical taxonomy and multivariate analysis system, version 2.1. Exeter Software, New York.

SANO, E.E., ROSA, R., BRITO, J.L.S. \& FERREIRA, L.G. 2010. Land cover mapping of the tropical savanna region in Brazil. Environmental Monitoring Assessment 166:113-124.

SILVA, S.R., SILVA, A.P., MUNHOZ, C.B., SILVA JUNIOR, M.C. \& MEDEIROS, M.B. 2001. Guia de plantas do Cerrado utilizado na Chapada dos Veadeiros. WWF Brasil, Brasília.

SILVA, J.F., FARIÑAS, M.R., FELFILI, J.M. \& KLINK, C.A. 2006. Spatial heterogeneity, land use and conservation in the cerrado region of Brazil. Journal of Biogeography 33:536-354 
SILVA, F.A.M, ASSAD, E.D. \& EVANGELISTA, B.A. 2008. Caracterização climática do bioma Cerrado. In Cerrado: ecologia e flora (S.M. Sano, S.P. Almeida \& J.F. Ribeiro, eds.). Embrapa-CPAC, Planaltina, p.71-88.

SIMON, M.F. \& PROENÇA, C. 2000. Phytogeographic patterns of Mimosa (Mimosoidea, Leguminosae) in the Cerrado biome of Brazil: an indicator genus of high-altitude centers of endemism? Biological Conservation 96:279-296.
SNEATH, P.H.A. \& SOKAL, R.R. 1973. Numerical taxonomy. W.H. Freeman, San Francisco.

WALTER, B.M.T. \& GUARINO, E.S.G. 2006. Comparação do método de parcelas com o "levantamento rápido" para amostragem da vegetação arbórea do Cerrado sentido restrito. Acta Botanica Brasilica 20:285-297.

WANDERLEY, M.G.L. 1989. Xyridaceae. In Flora do estado de Goiás (J.A. Rizzo, coord.). Coleção Rizzo v.11, p.9-81.

ZAR, J.H. 1999. Biostatistical analysis. Prentice Hall, New Jersey. 
